\title{
Prevalence of cross-fertilization in the hermaphroditic compound ascidian Diplosoma listerianum
}

\author{
J. S. Ryland, J. D. D. Bishop \\ Marine, Environmental and Evolutionary Research Group, School of Biological Sciences, University of Wales, Swansea \\ SA2 8PP, United Kingdom
}

\begin{abstract}
Experiments with several clones of Diplosoma listerianum (Milne Edwards) maintained in culture indicated that the majority produced sexual progeny (larvae) predominantly or exclusively by cross- rather than self-fertilization. The extent of true selfing, if any, was not established. Arrested oocyte development was observed in several clones kept in reproductive jsolation. Full oocyte development could be triggered in these by placing other genetic individuals in the same container, even though the different clones were not in physical contact.
\end{abstract}

\section{INTRODUCTION}

Hermaphroditism, with a substantial temporal overlap between male and female functions, is common in ascidians and several other sessile invertebrate groups (reviewed by Ghiselin 1974). This implies the potential for self-fertilization in these forms. Selfing is the most extreme form of inbreeding, reducing levels of heterozygosity almost to zero within a few generations (e.g. Falconer 1981). This increased homozygosity is generally accompanied by reduced fitness (inbreeding depression: reviewed by Charlesworth \& Charlesworth 1987). A dramatic inbreeding depression resulting from selfing in experimentally manipulated stocks of the ascidian Botryllus schlosseri has been reported by Sabbadin (1971). Complete selfing, maintained in the long term, will impose the same evolutionary inability to adapt to changing ecological conditions as affects parthenogenetic populations, but without the possibility of perpetuating heterozygote genotypes (Maynard Smith 1978).

On the other hand, selfing may be envisaged as conferring certain advantages in some settings, while the costs mentioned above may be ameliorated. Any form of inbreeding, if maintained over a number of generations, will tend progressively to purge deleterious recessive alleles from the population, so that inbreeding depression will be at least partially reduced. Selfing may represent an efficient means of fertilization in sessile forms, avoiding problems of sperm dilution in free-spawning species and of copulation or sperm uptake in species with internal fertilization. Isolated individuals, such as single colonisers of new habitat space, will be able to found a new population by sexual means if selfing is routine or is at least available as an 'emergency option'. Furthermore, any form of inbreeding in a sessile animal may perhaps allow the perpetuation of locally favourable genotypes which would be diluted or disrupted, causing outbreeding depression, by outcrossing (Shields 1982). This argument for habitual inbreeding is particularly pertinent to temporally stable but spatially heterogeneous habitats. Outbreeding depression has been reported by Grosberg (1987) in Botryllus schlosseri (in material belonging to a different population from that studied by Sabbadin 1971).

The extent to which selfing actually occurs may, therefore, reflect the balance of these costs and benefits in a particular ecological setting. Information on the extent of selfing in the Ascidiacea is incomplete and to some extent contradictory. Considering unitary (aclonal) species first, a prevalence of selfing has been inferred from circumstantial evidence in the North American brooding corellid Corella inflata by Lambert et al. (1981). The same authors reported that a majority of individuals of a second Corella species, C. willmeriana, proved self-fertile when gametes were mixed experimentally in seawater. However, natural self-fertilization in this free-spawning species seems much less 
probable than in C. inflata, since Lambert et al. (1981) reported that in $C$. willmeriana ova were released on average ca $5 \mathrm{~min}$ later than sperm. In a review of ascidian reproduction, Berrill (1975) stated that selffertilization was the norm in 3 ascidiid species, Phallusia mammillata, Ascidia mentula, and Ascidiella aspersa, but did not give references. Minganti (1948) had similarly stated that self-fertilization was 'a normal process' in the first 2 of these 3 species, again without citing evidence. Cloney (1987) asserted that all species of the families Ascidiidae and Corellidae were selffertile, and that many species of Styela (Styelidae) and Molgula (Molgulidae) were self-fertile, or at least partially so, in the laboratory. In constrast, a barrier to selffertility has been experimentally demonstrated in Ascidia ceratodes, although this barrier breaks down several hours after eggs are removed from the oviduct (Scofield et al. 1982a). Most individuals of the wellstudied oviparous species Ciona intestinalis (Cionidae) are self-sterile, the chorion being the site of recognition of self and non-self (Morgan 1923, Rosati \& De Santis 1978). Morris (1962) recorded low levels of self-fertilization and high levels of cross-fertilization in numerous in vitro trials with gametes of the pyurid Herdmania momus; the chorion was regarded as the site of the block to self-fertilization. A high level of self-sterility has also been reported in a second pyurid, Halocynthia roretzi, by Fuke (1983), again with the chorion suggested as the site of discrimination between autologous and heterologous sperm.

In contrast to unitary forms, the great majority of colonial ascidians brood their young, so that fertilization occurs within the colony. Lambert (1982) considered that the characteristic shape of sperm in colonial species (with a relatively short tail compared with sperm of unitary forms, implying reduced motility) suggested the occurrence of selfing without sperm leaving the zooid. Egg transport and initial embryonic cleavages have been observed to follow ovulation in isolated zooids of the perophorid Ecteinascidia turbinata, implying the occurrence of self-fertilization (Lambert 1982) However, 2 different mechanisms promoting cross-fertilization have been described in the compound styelid Botryllus. A gametic compatibility system, controlled by a single highly polymorphic locus and mediated by the diploid (maternal genotype) egg envelope, has been reported in certain populations by Oka (1970) and Scofield et al. (1982a, b). A second mechanism, involving functional protogyny within synchronised zooid generations, was described in $B$. schlosseri by Milkman (1967) and Sabbadin (1971). A similar pattern of zooid generations and gonad maturation was noted in three species of Botrylloides by Mukai et al. (1987), who concluded that selfing must therefore be absent in these forms.
The experiments reported here were intended to determine whether cross-fertilization occurs in the didemnid ascidian Diplosoma listerianum. The results are believed to constitute the first direct information on the mating system of any didemnid. $D$. listerianum has been widely recorded as an epibiotic and fouling organism of marine littoral and shallow sublittoral substrata along western European coasts and from the Mediterranean (Millar 1970). The distribution of the species beyond the European area is questionable, but if, as proposed by Rowe (1966), D. macdonaldi Herdman and $D$. rayneri Macdonald are synonyms of $D$. listerianum, then the species has a worldwide distribution, encompassing all continents except Antarctica.

Each colony of Diplosoma Listerianum is founded by the attachment and metamorphosis of a sexually produced tadpole larva. Asexual budding then produces a flat, incrusting colony of minute zooids within a common test. A zooid has both a testis, with 2 follicles, and an ovary. Mature gonads of both types generally occur simultaneously within a well-grown colony. However, Brunetti et al. (1988) reported that testes appear slightly before ovaries during colony development; colonies may therefore show slight adolescent protandry in the terminology of Ghiselin (1974). Sperm are released into the surrounding water via the common cloacal chamber of the colony. Ova are retained in the colony, with fertilization in situ, and embryos are brooded within the test. When $D$. listerianum is cultured in filtered seawater, the colonial test is virtually transparent, so that zooidal budding, testis development, and oocyte growth and maturation can be directly monitored in live material under the light microscope. Similarly, the occurrence and development of embryos in the test can be observed directly.

\section{MATERIAL AND METHODS}

The Diplosoma listerianum (Milne Edwards) colonies used in the experiments reported here were the sexual progeny of individuals colonising perspex and formica settlement panels in Queen's Dock, Swansea during the summer of 1988. Panels bearing well-grown colonies were removed from the dock during July and August, brought into the laboratory, and suspended in a $1000 \mathrm{l}$ seawater recirculating system consisting of a series of chambers arranged as a cascade and illuminated from above. Larvae released by the colonies settled and metamorphosed readily on the undersurface of $38 \times 76 \mathrm{~mm}$ glass microscope slides held horizontally just below the water surface in racks which shaded the slides from above (cf. Crisp \& Ghobashy 1971). Slides were examined every $2 \mathrm{~d}$, and those bearing a newly established colony were 
removed immediately and clipped vertically in a small polystyrene tank containing $750 \mathrm{ml}$ filtered seawater (FSW). At the time of removal of slides from the recirculating system occupied by the parent colonies, all new colonies were still at the 2 zooid (i.e. oozooid plus first blastozooid) stage that is reached upon metamorphosis in this species. Additional colonies were removed from slides on which more than one larva had settled.

Experiment 1. This experiment was intended to investigate the occurrence of selfing by comparing reproductive activity of colonies reared in isolation and in groups.

Four slides, each bearing a single newly established colony, were placed together in each of 5 tanks ('grouped colonies'). Slides originating from at least 2 different chambers of the recirculating system were grouped in this way, to reduce the probability that the grouped colonies were siblings. Twenty other colonies were placed in isolation in separate tanks ('isolated colonies'), in each case accompanied by 3 uncolonised glass slides. The tanks were placed in random order along 2 shelves in a constant temperature room maintained at $17^{\circ} \mathrm{C}$. A daily light: dark regime of $15: 9 \mathrm{~h}$ was imposed for the first $5 \mathrm{wk}$, followed by a 16:8 h regime. The water in the tanks on each shelf was gently agitated by vertical reciprocating paddles moved by a modified kymograph drive. Water was replaced with fresh FSW twice a week. After each water change, colonies were fed a mixture of equal volumes of 3 phytoplankton cultures (Rhodomonas balthica Karsten and Pavlova lutheri [Droop] Green, plus either Isochrysis galbana Parke or its tropical strain, T-ISO). The combined phytoplankton cell count in the tanks immediately following feeding was ca $200 \times 10^{3}$ cells $\mathrm{ml}^{-1}$, but declined rapidly thereafter. In addition. $\mathrm{ca}$ $0.02 \mathrm{ml}$ of Liquifry Marine (Liquifry Co. Ltd., Dorking, England), dispersed in $10 \mathrm{ml} \mathrm{FSW}$, was added to each tank 12 to 24 h before every water change.

Colonies were examined under a dissecting microscope at ca weekly intervals for $14 \mathrm{wk}$. The presence or absence of developing embryos or unreleased larvae in the colonial test was noted on each occasion. Two phases of development, each of ca $1 \mathrm{wk}$ duration (see 'Development times'), were scored separately: all stages earlier than the point at which a segmented tail encircled the embryo ('embryos' below); and stages from the differentiation of a segmented tail to the release of the larva ('larvae'). The number of zooids in each colony was counted in Weeks 4 to 11 of the experiment, except for large colonies (>500 zooids), which could not be counted accurately.

By the end of this period, each colony had grown to at least 60 zooids (many isolated colonies exceeding 500 zooids), and had generally divided into a number of fragments. Whole colonies or fragments moved about slowly, as reported by Della Valle $(1900,1908)$ and Carlisle (1961), but were not permitted to pass onto another slide or onto the walls of the culture tanks.

Experiment 2. This experiment was intended to establish whether colonies that did not reproduce in isolation in Expt 1 would do so when grouped with other genetic individuals; the results are therefore representative only of non-reproductive isolated colonies from the first experiment. To enable a degree of replication, and to permit an experimental design in which the degree of crowding was equal in both treatments, each colony was divided into a number of pieces, referred to below as ramets.

Twelve of the 20 isolated colonies produced no larvae during Expt 1 (see 'Results'). Six of these unproductive colonies, referred to henceforth at Clones $1,6,7,8$, 23 , and 25 , were then cut into a number of ramets of approximately the same size, and detached from the slide on which they had grown using a sharp razor blade. The ramets were allowed to reattach individually to clean slides, each being held in contact with its slide for $48 \mathrm{~h}$ with a loop of thin nylon monofilament fishing line. For each of the 6 clones, 3 slides bearing a ramet of the same clone were placed together in a tank ('single-clone tanks' below). In addition, 3 slides bearing ramets of different clones were placed together in each of 4 other tanks ('mixed-clone tanks' below). Each ramet was observed under the dissecting microscope at ca weekly intervals for $9 w \mathrm{k}$, and the number of brooded embryos or unreleased larvae in the test noted on each occasion. The presence of vitellogenic oocytes, defined for these purposes as those oocytes with a diameter of 130 um or more, was also recorded. The development of individual larvae was not traced in this material, but larvae being brooded in the test at the time of one observation were considered to have been released by the next (see data below on development times). The number of young colonies (from larvae released during the week) established on each slide was noted each occasion that observations were made, after which these new colonies were removed. All new colonies established from larvae settling on the walls of each culture tank during the experiment were counted after 8 wk.

Precautions. Precautions were taken throughout both experiments to minimise the probability that water was transferred from 1 tank to another during water changes, feeding, or observation. For instance, lids were placed on all tanks during water changes to prevent entry of drops or splashes from other tanks Food was administered to each tank from a different syringe, the syringes being washed and dried between use. For observation under the microscope, slides from each tank were placed in a different container. 
Development times. The data given below on rates of embryonic development in the colonial test were gathered in the course of subsequent experiments that will be reported elsewhere. Numerous ramets of Clones 7 and 23 were cultured by the methods outlined above, and the embryos brooded by each ramet were mapped daily and their development followed during daily observations maintained for ca $3 \mathrm{wk}$.

\section{RESULTS}

Zooid generations within the colony were not synchronised in the material studied here. Nor was a colony-wide vascular or ampullary system apparent; ampullae appeared to arise individually, direct from a zooid.

\section{Experiment 1}

More colonies reared in groups produced larvae at some time during the period of observation than did those reared in isolation, as shown in Fig. 1. This would be the expected pattern if self-fertilization were relatively rare, with cross-fertilization the predominant mode for the production of sexual progeny. If, con-

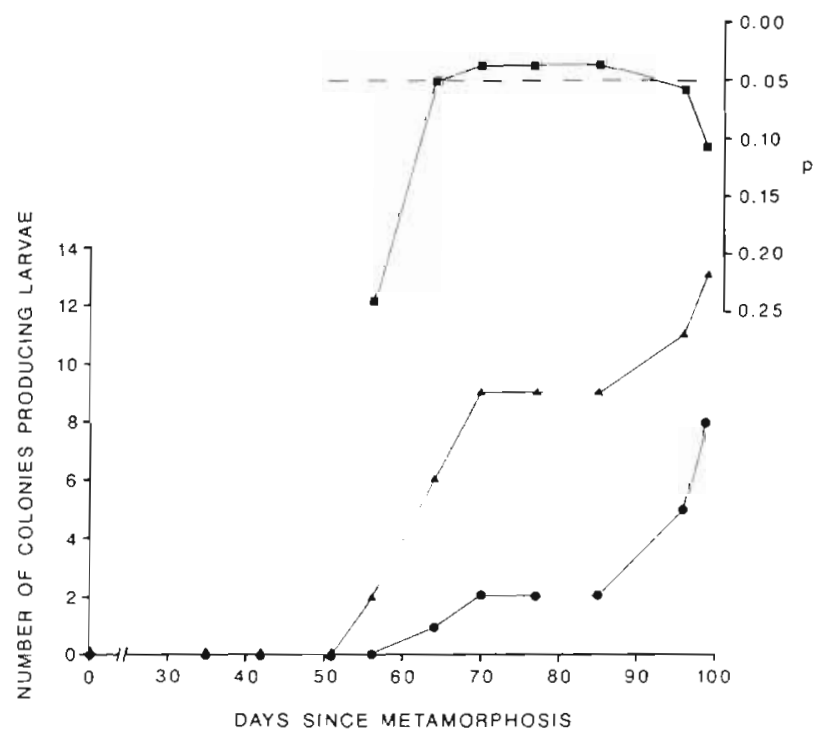

Fig. 1. Diplosoma listerianum. Expt 1: cumulative number of grouped ( $\wedge$ ) and isolated $(\bullet$ colonies producing larvae at some tume during the period of observation (larval production by a particular colony was not generally contunuous): 20 colonies of each category were observed. Also shown (-) is probability (p) of obtaining, through chance alone, an excess of grouped colonies as great as or greater than that observed, if grouping or isolation had no effect (Fisher's $2 \times 2$ exact test, $Z$ approximation, 1-tailed; calculated according to Meddis 1975) versely, selfing were prevalent, no difference between grouped and isolated colonies would be predicted purely from consideration of reproductive biology. A 1 tailed test for the significance of the observed difference therefore seems appropriate, and yields significant values for a considerable part of the period of observation (Fig. 1).

However, the grouping of colonies may have affected reproduction in other, indirect ways. Isolated colonies appeared to reach a larger maximum size than grouped colonies (Fig. 2). A Kolmogorov-Smirnov (K-S) 2-sample test (Sokal \& Rohlf 1981) indicates a significant difference if all 20 grouped colonies are included in the comparison $\left(\mathrm{n}_{1}=20, \mathrm{n}_{2}=20 ; \mathrm{D}=0.85 ; \mathrm{p}<0.001\right)$. It is very doubtful, however, whether colonies grouped in the same culture tank should be treated as independent observations in this way, even though no tank effects on maximum colony size within the grouped material are apparent (1-way ANOVA, Sokal \& Rohlf 1981: $\mathrm{F}_{\mathrm{s}}=0.114,4$ and $15 \mathrm{df}, \mathrm{p}>0.75)$. Repeating the $\mathrm{K}-\mathrm{S}$ test using only the largest single colony in each of the 5 grouped culture tanks, which will minimize the observed difference between grouping and isolation, yields a marginally significant resuit $\left(\mathrm{n}_{1}=5, \mathrm{n}_{2}=20 ; \mathrm{D}=0.65 ; \mathrm{p}=0.05\right)$.

\section{Experiment 2}

The majority of ramets, which had all been drawn from 4-mo-old colonies grown in reproductive isolation during Expt 1, did not have vitellogenic oocytes at the start of Expt 2 (Fig. 4). All 6 ramets of Clone 23, however, had vitellogenic oocytes from the start. Vitellogenic oocytes appeared in all ramets of Clones 1, 7, 8 and 25 in mixed-clone tanks during the period of observation. In contrast, the majority of ramets in singleclone tanks (not counting those of Clone 23) failed to produce vitellogenic oocytes during the experiment. Vitellogenic oocytes and brooded embryos or larvae were not observed in any ramet of Clone 6 throughout. In mixed-clone tanks, every ramet of the remaining 5 clones $(1,7,8,23$ and 25$)$ produced larvae; in contrast, single ramets of only 2 clones $(1,25)$ produced a small number of larvae in single-clone tanks (Figs. 3 and 4). In mixed-clone tanks (Fig. 4A), the number of ramets having larvae rose alongside the number having vitellogenic oocytes, with a lag of 2 to 3 wk between the 2 categories, reflecting normal development times. In contrast, in single-clone tanks (Fig. $4 \mathrm{~B}$ ), the number of ramets having larvae did not keep pace in this way. because vitellogenic oocytes or embryos were produced but failed to undergo normal development to larvae in Clone 7 (2 ramets) and Clone 23 (all 3 ramets).

As argued for Expt 1, a deviation in the results in the direction opposite to that observed cannot be predicted 


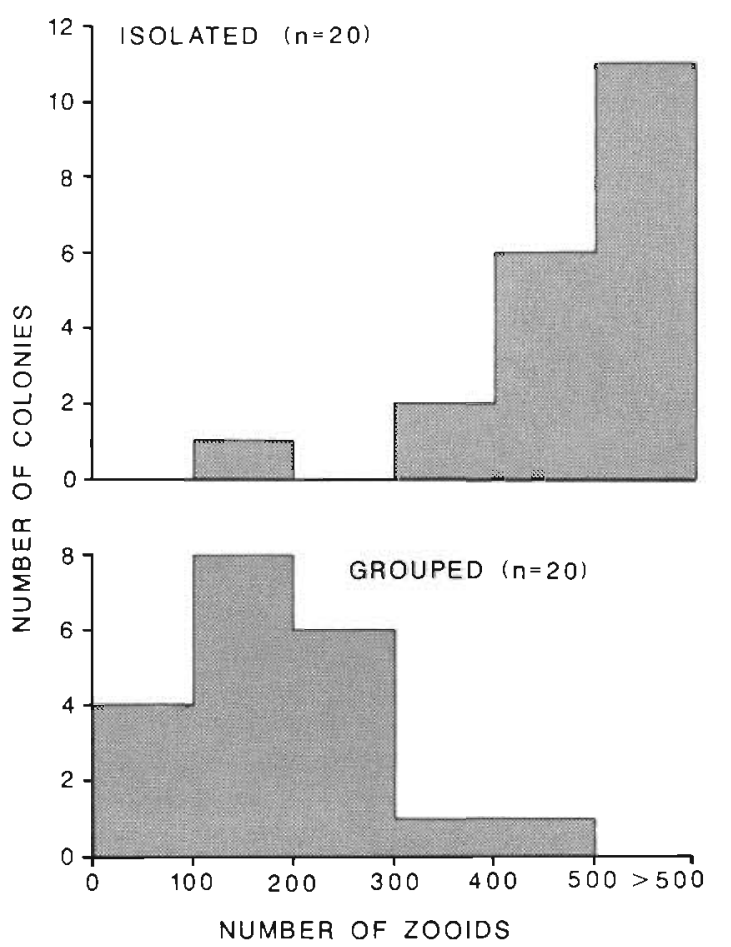

Fig. 2. Diplosoma listerianum. Expt 1: frequency distribution of maximum colony size (number of zooids) of isolated and grouped colonies reached at any time during Weeks 4 to 11 of observation (some colonies decreased in size after reaching their maximum)

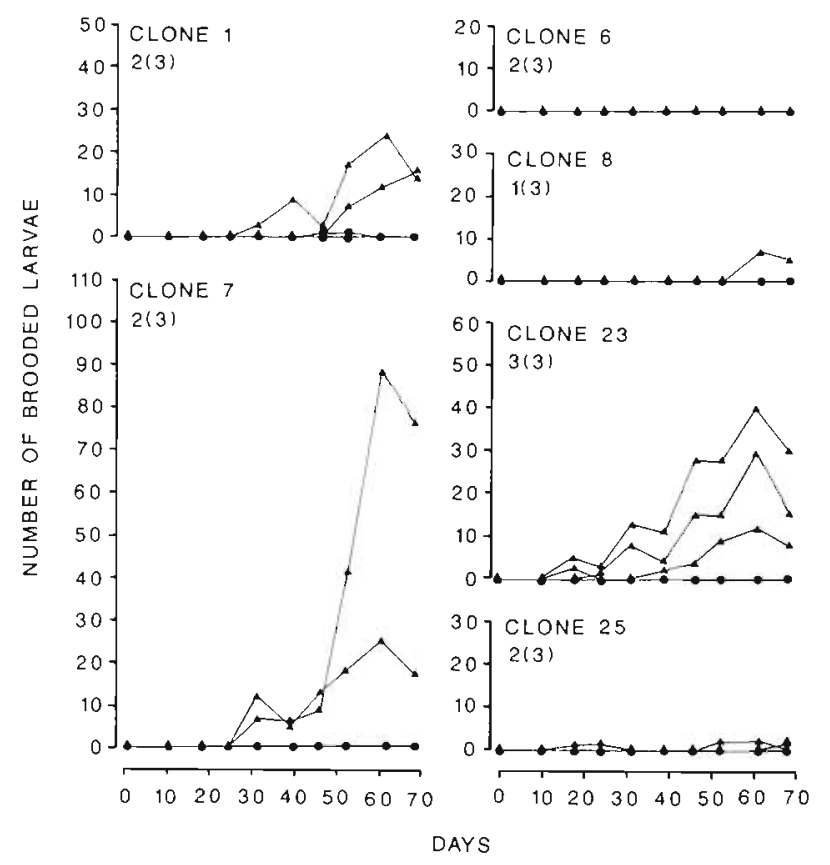

Fig. 3. Diplosoma listerianum. Expt 2: number of larvae being brooded by individual ramets of each clone in mixed-clone ( $\mathbf{\Delta}$ and single-clone ( $)$ tanks on each occasion observations were made. Number of ramets of each clone observed is indicated thus: mixed-clone tanks (single-clone tanks)

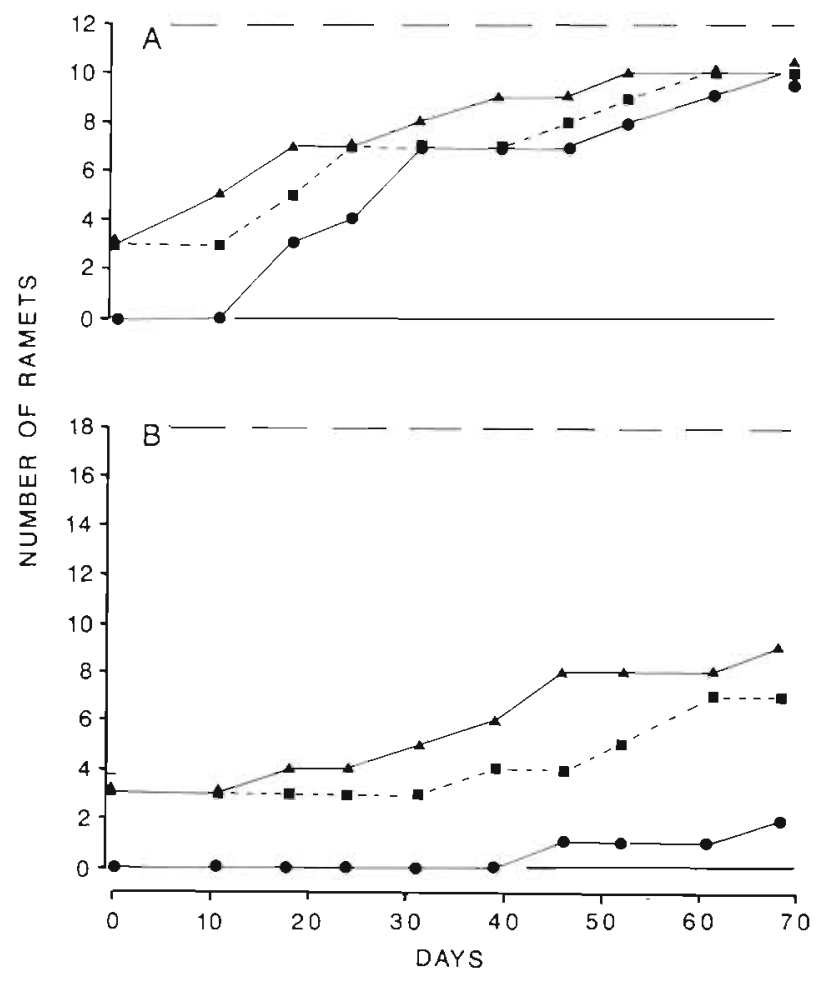

Fig. 4. Diplosoma listerianum. Expt 2: cumulative number of ramets of all clones having vitellogenic oocytes $(\mathbf{\Lambda})$, and brooded embryos $(\boldsymbol{\bullet})$ or larvae $(\bullet)$ at some time during the period of observation (reproduction by a particular ramet was not necessarily continuous). (A) Ramets in mixed-clone tanks (B) Ramets in single-clone tanks. NB. total number of ramets studied in mixed-and single-clone tanks was not the same: number indicated by dashed line

from consideration of possible fertilization systems. A 1 -tailed test of the results is therefore appropriate. Considering each clone as one item of data, the results demonstrate a significant trend $5: 0$, with one null result) for the greater production of larvae by ramets in mixed-clone tanks, both in terms of the proportion of ramets producing any larvae and in terms of the number of larvae produced per fertile ramet (Sign-test, 1 -tailed, $p<0.05$, Sokal \& Rohlf 1981). A total of 723 larvae were brooded by the 12 ramets in mixed-clone tanks during the entire period of observation, but only 3 by the 18 ramets in single-clone tanks. No new colonies from metamorphosed larvae were seen in single-clone tanks, while 362 were recorded in the mixed-clone tanks after $8 \mathrm{wk}$.

\section{Development times}

Brooded embryos developed segmented tails about $7 \mathrm{~d}$ after ovulation (mean and sd for Clone $7=6.60$ [0.58] di Clone $23=7.01$ [0.60] d) (Fig. 5). The differ- 
ence of means between the 2 clones was statistically significant (2-tailed t-test, $t_{\mathrm{s}}=4.31,151 \mathrm{df}, \mathrm{p}<0.001$ ) Larvae were subsequently retained in the test for ca $6 \mathrm{~d}$ between the appearance of a segmented tail and release, with development in Clone 23 again being significantly slower (Clone $7=6.03[0.75] \mathrm{d}_{\text {; }}$ Clone 23 $\left.=6.51[0.73] \mathrm{d}_{;} \mathrm{t}_{\mathrm{s}}=3.03,87 \mathrm{df}, \mathrm{p}<0.01\right)$. Larvae were released ca $13 \mathrm{~d}$ after ovulation, again with a slight but significant difference between clones (Clone $7=12.66$ $\{0.78] \mathrm{d}_{i}$ Clone $23=13.39[0.63] \mathrm{d}_{i} \mathrm{t}_{\mathrm{s}}=4.75 .87 \mathrm{df}$, $\mathrm{p}<0.001)$.

It is apparent from the data on embryonic development times presented here that the total number of larvae produced by ramets during Expt 2 must have been somewhat under-estimated. This is because brooded larvae were counted roughly weekly (mean interval between observations $7.1 \mathrm{~d}$ during the relevant period), whereas larvae were retained in the colonial test for rather less than $7 \mathrm{~d}$ between the appearance of a segmented tail (at which time they were first scored

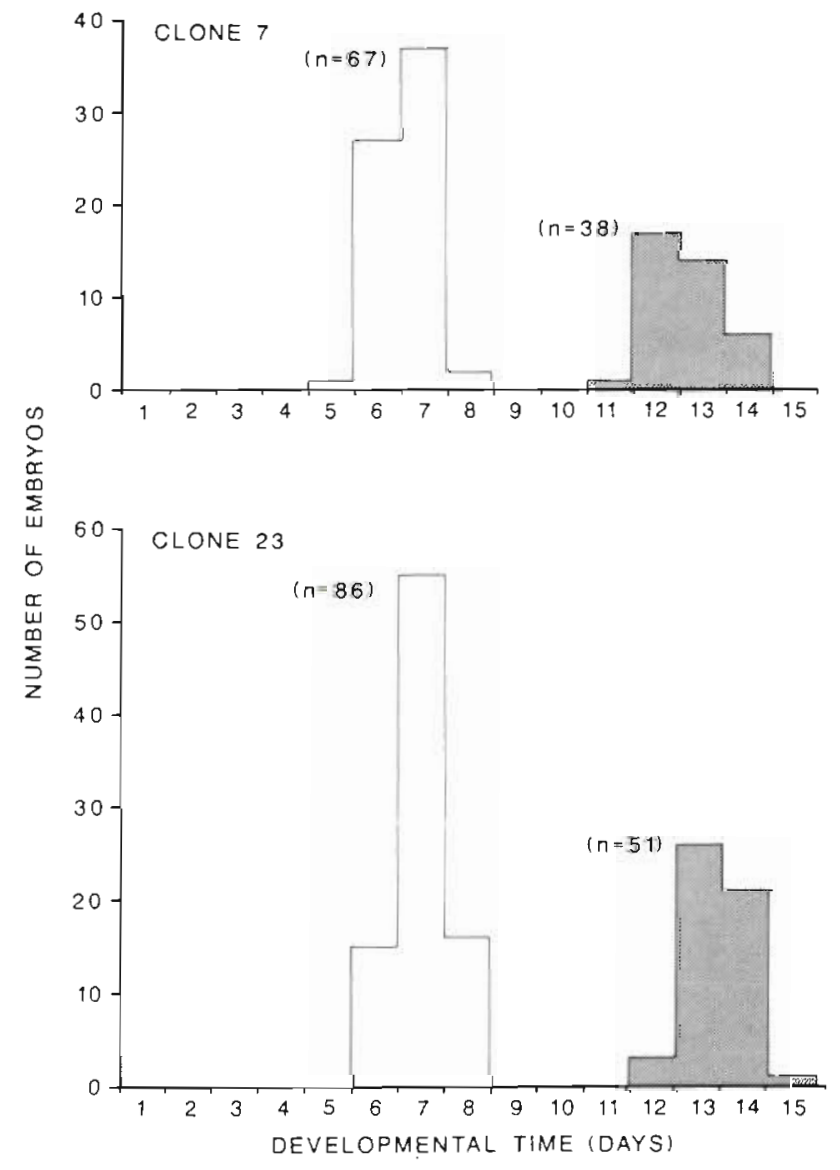

Fig. 5. Diplosoma listenanum. Frequency distribution of development times of embryos brooded in test in 2 clones. Open bars: time from ovulation to differentiation of segmented tail. Stippled bars. ume from ovulation to release of larva. as larvae) and release. Some individuals would, therefore, have escaped the count. Furthermore, the number of colonies founded from larvae released during the first $8 \mathrm{wk}$ of the experiment would have been reduced by loss of unmetamorphosed larvae during the twiceweekly water changes. However, both these discrepancies would have applied equally to the material in single-clone and mixed-clone tanks, so that comparison between the 2 treatments remains valid.

\section{DISCUSSION}

The results of Expts 1 and 2 suggest that crossfertilization is the predominant mechanism by which sexual progeny are produced in Diplosoma listerianum. Nevertheless, a considerable amount of selfing (production of larvae by isolated colonies) was recorded in Expt 1. The data from Expt 2 were much more clear-cut, with very low levels of selfing. It must be emphasised that it is not yet established how much of the apparent selfing in either experiment is genuine. Part or all of it might have arisen from inadvertent cross-fertilization brought about by the transfer of sperm between tanks in smears or droplets of seawater during activities associated with the culture or observation of colonies. If such lapses of experimental hygiene were responsible for all the apparent selfing, it appears that fewer errors occurred during Expt 2. If, however, at least a part of the reported selfing were genuine, the lower overall level of selfing in Expt 2 might reflect differences between the reproductive behaviour of various genetic individuals: the clones used in the second experiment were produced from 6 colonies chosen at random from the 12 isolated colonies that had not produced larvae during the first. The remaining 8 colonies that showed apparent selfing in the first experiment were not represented in the second. The results of Expt 2 may, therefore, only be representative of the reproductive behaviour of slightly more than half of the original sample of colonies. It is apparent that in these, selfing was rare even in the absence of opportunities for outcrossing.

The design of Expt 2 was superior to that of Expt 1 because in it the level of crowding of grouped and isolated material was the same. The discrepancy in colony size between isolated and grouped material in Expt 1 seems to render comparison between the reproduction of the 2 classes less valid, although this depends upon the presumed reason for the difference. The difference may have arisen because more food was available to an isolated colony than to a grouped colony (since the same amount of food was administered to each tank). It is not apparent how this difficulty could be overcome simply, while retaining the same basic expen- 
mental design. For instance, to provide the same amount of food per colony, i.e., putting 4 times more food in grouped-colony tanks, might not compensate perfectly, given the probable dependence of feeding efficiency upon particle concentration. Questions of resource partitioning within the colony are also pertinent. It is possible that resource allocation within the colony is influenced by food supply. For instance, an abundant food supply to a newly founded colony may conceivably stimulate the channelling of available resources predominantly or exclusively to modular replication

Alternatively, food supply may not have been the dominant factor in determining the rate of colony growth, and the more extensive somatic growth of isolated colonies may simply have reflected the lower level of investment of resources in sexual reproduction in the absence of opportunities for outcrossing. In itself, this latter suggestion would imply that differences in the rate of colony growth do not invalidate comparison between larval production of isolated and grouped colonies, since the discrepancies in colony size are seen as a consequence of the level of sexual reproductive activity and not vice versa.

A second advantage of Expt 2 over Expt 1 arose from the division of each colony into several ramets. This enabled the same genetic individual to be subjected simultaneously to both treatments (single-clone and mixed-clone tanks) and to be represented in more than one mixed-clone tank. Thus it could be demonstrated that (with the exception of Clone 6) the failure of clones to reproduce in isolation was not attributable to immaturity or defect, since ramets of the same clones were reproducing at the same time in grouped-clone tanks. It was also apparent that the absence or rarity of selfing in reproductive isolation was not dependent upon the physical continuity of the colony (unlike the mechanism of synchronised protogyny of zooids in Botryllus schlosseri. Sabbadin 1971), since 3 separate ramets were present in each single-clone tank. Furthermore, it was possible to detect differences in reproductive behaviour, presumably genetically determined, between genetic individuals in a way that was not possible when undivided colonies were subjected to one treatment apiece as in Expt 1. Thus, only in ramets of Clones 7 and 23 did oocytes undergo complete vitellogenic growth in reproductive isolation, to reach a diameter of ca $300 \mu \mathrm{m}$. In ramets of other clones, oocyte growth was halted a diameter of ca $120 \mu \mathrm{m}$ (i.e. ca $0.4 \times$ the final diameter at ovulation) in the absence of another clone. In Clone 6, vitellogenic oocyte growth was lacking in all ramets. Differences between clones were also apparent in the rate of production of larvae in mixed-clone tanks, with Clones 7 and 23 producing numerous larvae and Clones 6, 8 and 25 producing none or a few (Fig, 3).
Brunetti et al. (1988), studying Diplosoma listerianum from the Lagoon of Venice, Italy, maintained at $18 \pm$ $1{ }^{\circ} \mathrm{C}$, reported a mean development time from ovulation to larval release of $15.45 \mathrm{~d}$, somewhat longer than the values recorded here for material cultured at $17^{\circ} \mathrm{C}$ (ca $13 \mathrm{~d}$ ). A delay of 2 to $3 \mathrm{~d}$ between ovulation and the onset of embryonic cleavage was observed in the Venetian material, whereas early divisions were well underway $24 \mathrm{~h}$ after ovulation in Welsh specimens. This suggests that rates of development were very similar in the 2 sets of material once embryonic divisions had commenced. Berrill (1935) reported a time from fertilization to larval release of $17.5 \mathrm{~d}$ at $16^{\circ} \mathrm{C}$ in material referred to $D$. listerianum gelatinosum from Plymouth (England).

Arrested oocyte development was observed in several clones of Diplosoma listerianum kept in reproductive isolation. This is paralleled in some Bryozoa, as provisionally reported by Cancino et al. (1989). In each case, full oocyte development could be triggered by the presence, in the same container, of other genetic individuals, even though the different clones were not in physical contact.

In contrast, no such cessation of oocyte growth was observed in Clone 23 during these experiments. In single-clone tanks, numerous fully grown vitellogenic oocytes of this clone were produced and became embedded in the test in the normal way after ovulation, but subsequent development was restricted to a few irregular cellular divisions, followed by premature expuision from the ramet. Development and ovulation of a few fully-grown oocytes also occurred in 2 isolated ramets of Clone 7 during Expt 2, but again did not result in the production of larvae. It is not known whether sperm entry or syngamy had occurred in these instances, i.e. whether the failure of development after ovulation represented the consequence of non-fertilization or a lethal effect of selfing. Self-nonself recognition in ascidians has been described in 2 contexts, colony fusion and gametic compatibility (e.g. Scofield et al. 1982a, b). Furthermore, the settlement of larvae of Botryllus schlosseri is influenced by kin-recognition processes governed by the same highly polymorphic histocompatibility locus that regulates fusion of adult colonies in this species (Grosberg \& Quinn 1986). It is possible that, in brooding species, allorecognition affects the outcome of a fourth interaction, that between the embryo and the mother, as suggested by Burnet (1971). This seems feasible in the Didemnidae, in which embryos are brooded in intimate contact with the colonial test. Therefore, the possibility can not be discounted that the failure of development of eggs and their premature ejection from ramets of Clones 23 and 7 kept in reproductive isolation resulted from rejection of the embryo by the maternal test. Such a system 
would parallel the influence of foetal-maternal histocompatibility interactions upon foetal survival in mammals (reviewed by Jones \& Partridge 1983).

Acknowledgements. This work was supported by NERC Grant GR3/6553'A to J. S. Ryland. The figures were prepared by P. J. Llewellyn.

\section{LITERATURE CITED}

Berrill, N. J. (1935). Studies in tunicate development. III Differential retardation and acceleration. Phil. Trans. R. Soc. (Ser. B) 225: 255-326

Berrill, N. J. (1975). Chordata: Tunicata. In: Giese, A. C., Pearse, J. S. (eds.) Reproduction of marine invertebrates, Vol. 2. Academic Press, New York, p. 241-282

Brunetti, R., Bressan, M., Marin, M., Libralato, M. (1988). On the ecology and biology of Diplosoma listerianum (Milne Edwards, 1841) (Ascidiacea, Didemnidae). Vie Milieu 38 123-131

Burnet, F. M. (1971). 'Self-recognition' in colonial marine forms and flowering plants in relation to the evolution of immunity. Nature, Lond. 232: 230-235

Cancino, J. M., Castañeda, B., Orellana, M. C. (1989). Experiments on the effects of con-specific neighbours on the timing of sexual reproduction in bryozoans. In: Bigey, F. P. d'Hondt, J -L. (eds.) Abstracts vol, 8th Conf. int. Bryozool Ass., Paris, p. 66

Carlisle, D. B. (1961). Locomotory powers of adult ascidians. Proc. zool. Soc. Lond. 136: 141-146

Charlesworth, D., Charlesworth, B. (1987). Inbreeding depression and its evolutionary consequences. A. Rev. Ecol. Syst. 18: $237-268$

Cloney, R. A. (1987). Phylum Urochordata, Class Ascidiacea In: Strathmann, M. F. (ed.) Reproduction and development of marine invertebrates of the northern Pacific coast. University of Washington Press, Seattle, p. 607-639

Crisp, D. J., Ghobashy, A. F. A. A. (1971). Responses of the larvae of Diplosoma listerianum to light and gravity. In: Crisp, D. J. (ed.) 4th Eur mar. biol. Symp., Cambridge University Press, Cambridge, p. 443-465

Della Valle, A. (1900). Osservazioni intorno alle migrazioni delle colonie di Diplosoma listeri. Monit. zool. ital. 11 (suppl): 33-34

Della Valle, A. (1908). Osservazioni su alcune ascidie del Golto di Napoli. Atti Accad. Sci. fis. mat., Napoli 13 (Ser 2a): $1-89$

Falconer, D. S. (1981). Introduction to quantitative genetics, 2nd edn. Longman, London

Fuke, M. T (1983). Self and non-self recognition between gametes of the ascidian. Halocynthia roretzi. Wilhelm Roux Arch. dev. Biol. 192: 347-352

Ghiselin, M. T (1974). The economy of nature and the evolution of sex. University of California Press, Berkeley

Grosberg. R. K. (1987). Limited dispersal and proximity-

This article was presented by Dr R. N. Hughes, Bangor, UK dependent mating success in the colonial ascidian Botryllus schlosseri. Evolution, Lawrence, Kansas 41. 372-384

Grosberg, R. K., Quinn, J. F. (1986). The genetic control and consequences of kin recognition by the larvae of a colonial marine invertebrate. Nature. Lond. 322: 456-459

Jones, J. S., Partridge, L. (1983). Tissue rejection: the price of sexual acceptance? Nature, Lond. 304: 484-485

Lambert, C. C. (1982). The ascidian sperm reaction. A.m. Zool. 22: $841-849$

Lambert, G., Lambert, C. C., Abbott, D. P. (1981). Corella species in the American Pacific Northwest: distinction of C. inflata Huntsman, 1912 from C. willmeriana Herdman, 1898 (Ascidiacea, Phlebobranchia). Can. J. Zool. 59: 1493-1504

Maynard Smith, J. (1978). The evolution of sex. Cambridge University Press, Cambridge

Meddis, R. (1975). Statistical handbook for non-statisticians. McGraw-Hill, London

Milkman, R. (1967). Genetic and developmental studies on Botryllus schlosseri. Biol. Bull. mar. biol. Lab., Woods Hole 132: $229-243$

Millar, R. H. (1970). British ascidians. Synopses Br. Fauna (n.s.) 1: 1-92

Minganti, A. (1948). Interspecific fertilization in ascidians. Nature, Lond. 161: 643-644

Morgan. T. H. (1923). Removal of the block to self-fertilization in the ascidian Ciona. Proc natn. Acad. Sci. U.S.A. 9: $170-174$

Morris, J. E. (1962). A 'fertilization membrane' in the ascidian Herdmania momus and its relation to self- and crossfertilization. Experientia 18: 567-568

Mukai, H., Saito, Y., Watanabe, H. (1987). Viviparous development in Botrylloides (compound ascidians). J, Morph. 193: 263-276

Oka, H. (1970). Colony specificity in compound ascidians. In: Yukawa, H. (ed.) Profiles of Japanese science and scientists. Kodansha, Tokyo, p. 196-206

Rosati, F., De Santis, R. (1978). Studies on fertilization in the ascidians. 1 . Self-sterility and specific recognition between gametes of Ciona intestinalis. Expl Cell Res. 112: 111-119

Rowe, F. W. E. (1966). A review of the genus Diplosoma Macdonald, 1859. (Ascidiacea: Didemnidae) with a description of the proposed neotype of Diplosoma listerianum (Milne Edwards), 1841. Ann. Mag nat. Hist. (Ser 13) $9: 457-467$

Sabbadin, A. (1971). Self- and cross-fertilization in the compound ascidian Botryllus schlosseri. Devl Biol. 24 : 379-391

Scofield, V L., Schlumpberger, J. M., Weissman, I. L. (1982a). Colony specificity in the colonial tunicate Botryllus and the origins of vertebrate immunity. Am. Zool. 22: 783-794

Scofield, V. L., Schlumpberger, J. M., West, L. A., Weissman, I. L. (1982b) Protochordate allorecognition is controlled by a MHC-like gene system. Nature, Lond. 295: 499-502

Shields, W. M. (1982). Philopatry, inbreeding and the evolution of sex. State University of New York Press, Albany

Sokal, R. R., Rohlf, F. J. (1981). Biometry, 2nd edn. Freeman, New York

Manuscript first received: October 4, 1989

Revised version accepted: December 22, 1989 